Artigo

\title{
Lousa digital e aula de matemática: movimentos de aprendizagem em uma turma de primeiro ano do ensino médio
}

\author{
Digital whiteboard and math class: learning movements in a first-year high school \\ class
}
Pizarra digital y clase de matemáticas: movimientos de aprendizaje en una clase de primer año de secundaria

\author{
Sérgio Freitas de Carvalho ${ }^{1}$ \\ D [0000-0002-4672-4720] \\ Suely Scherer ${ }^{2}$ \\ [0000-0002-2213-3803]
}

\begin{abstract}
Resumo
Neste artigo tem-se como objetivo apresentar e discutir alguns movimentos de aprendizagem com o uso de Lousa Digital que ocorreram durante um estudo sobre área de retângulos, em uma aula de matemática de uma turma de Ensino Médio. Os dados apresentados neste texto foram produzidos em uma pesquisa de doutorado, em que se analisou como ocorrem movimentos de aprendizagem com Lousa Digital em aulas de matemática, em uma turma de oitavo ano e em uma turma de primeiro ano do Ensino Médio, ambas em escolas públicas de Campo Grande - MS. A análise dos dados foi orientada por uma proposta de articulação teórica construída na pesquisa, denominada Ciclo de Ações Coletivo, baseada em estudos de José Armando Valente, Jaan Valsiner e na obra Parangolé, do artista plástico Hélio Oiticica. Observamos, a partir da discussão realizada, que o uso da Lousa Digital, ao favorecer o compartilhamento de ideias, oportunizou movimentos individuais e coletivos de aprendizagem no grupo de alunos. Movimentos que representam Parangolés de Ações, que se constituem a partir interações entre indivíduos e destes com a Lousa Digital, e que vão constituindo Ciclos de Ações Coletivos.
\end{abstract}

Palavras-chave: Lousa digital. Parangolé de ações. Aula de matemática.

\begin{abstract}
This article aims to present and discuss some learning movements with the Digital Whiteboard use that occurred during a study about rectangles area, in a math class of a high school class. The data presented in this text were produced in a doctoral research, in which it was analyzed how learning movements with Digital Whiteboard in mathematics classes occur, in an eighth grade class of elementary school and in a first year high school class, both in public schools of Campo Grande - MS. The data analysis was guided by a theoretical articulation proposal, built in the research, called the Collective Actions Cycle, based on studies by José Armando Valente, Jaan Valsiner and on the work Parangolé, by the plastic artist Hélio Oiticica. We observed, from the discussion carried out, that the Digital Whiteboard use, by favoring the sharing of ideas, enabled individual and collective learning movements in the students group. Movements that represent Parangolés de Ações, that are
\end{abstract}

1 sergio.carvalho@ifms.edu.br, Doutor em Educação Matemática, Professor do Ensino Básico, Técnico e Tecnológico, Instituto Federal de Mato Grosso do Sul, Nova Andradina/Mato Grosso do Sul/Brasil.

2 susche@gmail.com, Doutora em Educação: Currículo, Professora Associada, Universidade Federal de Mato Grosso do Sul, Campo Grande/Mato Grosso do Sul/Brasil. 
constituted from interactions between individuals and between them with the Digital Whiteboard, and that constitute Collective Actions Cycles.

Keywords: Digital whiteboard. Parangolé of actions. Math class.

\section{Resumen}

This article aims to present and discuss some learning movements with the Digital Whiteboard use that occurred during a study about rectangles area, in a math class of a high school class. The data presented in this text were produced in a doctoral research, in which it was analyzed how learning movements with Digital Whiteboard in mathematics classes occur, in an eighth grade class of elementary school and in a first year high school class, both in public schools of Campo Grande - MS. The data analysis was guided by a theoretical articulation proposal, built in the research, called the Collective Actions Cycle, based on studies by José Armando Valente, Jaan Valsiner and on the work Parangolé, by the plastic artist Hélio Oiticica. We observed, from the discussion carried out, that the Digital Whiteboard use, by favoring the sharing of ideas, enabled individual and collective learning movements in the students group. Movements that represent Parangolés de Ações, that are constituted from interactions between individuals and between them with the Digital Whiteboard, and that constitute Collective Actions Cycles.

Palabras claves: Digital whiteboard. Parangolé of actions. Math class.

\section{Introdução}

A presença de Lousas Digitais em contextos escolares tem feito com que investigações sobre o uso desta tecnologia se tornem mais frequentes e contribuam para constituição do cenário de pesquisa no âmbito do uso de tecnologias digitais em situações de ensino e aprendizagem. As investigações sobre o uso desta tecnologia digital têm atraído o interesse de pesquisadores em diferentes aspectos, tais como formação de professores para o seu uso, contribuições para aprendizagem, potenciais e limitações técnicas, dentre outros.

No âmbito da formação de professores e práticas docentes podem ser mencionados trabalhos como o de Flores, Mussoi e Falkemback (2018), no qual se discute aspectos de uma capacitação para o uso da Lousa Digital em salas de informática no Município de Santa Maria - RS; o estudo de Costa, Puggian e Vilaça (2017), que discute possibilidades de práticas docentes com Lousa Digital em aulas de Língua Inglesa; e, ainda, os diversos estudos de Marco Aurélio Kalinke e seus colaboradores. Dentre esses últimos podemos mencionar Navarro e Kalinke (2016), e Ribeiro, Kalinke e Santos (2017), que são resultados de estudos desenvolvidos com professores da Rede Estadual de Ensino do Paraná, no âmbito da formação continuada de professores.

No que diz respeito aos aspectos técnicos da Lousa Digital, ajudam a compor este cenário de pesquisa trabalhos como Mazzi, Siqueira e Borba (2012), em que se analisa características de uma marca específica de Lousa Digital e aponta-se algumas limitações técnicas para seu uso, em especial em aulas de matemática, como por exemplo a baixa precisão do toque e da escrita da caneta. Pode-se mencionar ainda a pesquisa de Fiscarelli, Morgado e Felix (2016), em que se avaliam diferentes objetos de aprendizagem da Lousa Digital voltados para o ensino de matemática. 
Temos ainda estudos que buscam na literatura identificar dificuldades de professores no uso da Lousa Digital (SILVA et al., 2017), e possibilidades de uso em aulas de matemática (SEBASTIÃO; GIACOMAZZO, 2018).

Em meio a esse cenário, nosso interesse pela temática do uso da Lousa Digital se iniciou com nossa pesquisa de mestrado (CARVALHO, 2014), na qual tivemos como foco analisar uma formação continuada em serviço de professores para discutir o uso desta tecnologia em aulas de matemática.

Desde o início, o que impulsionou nossas pesquisas foi o fato da Lousa Digital poder ser compreendida como uma tecnologia de uso coletivo, como um computador de uso coletivo (uma vez que vários alunos podem usar a mesma tecnologia em sala), que poderia favorecer processos de construções coletivas de conhecimentos a partir da interação entre sujeitos e destes com a Lousa Digital.

Essa característica de uso da Lousa, juntamente com algumas constatações feitas em (CARVALHO, 2014), nos mobilizou para o desenvolvimento da pesquisa de doutorado (CARVALHO, 2019), pesquisa na qual os dados que discutimos neste artigo foram produzidos e analisados. O objetivo dessa pesquisa de doutorado foi analisar como ocorrem movimentos de aprendizagem com Lousa Digital em aulas de matemática. Para realizar tal análise, em um movimento imbricado entre análise e construção teórica da pesquisa, foi apresentada uma proposta teórica para o uso da Lousa Digital denominada de Ciclo de Ações Coletivo, orientada por estudos de José Armando Valente (sobre o Ciclo de Ações), Jaan Valsiner (sobre a Psicologia Cultural) e pela obra Parangolé, do artista plástico Hélio Oiticica.

Os dados da pesquisa foram produzidos em aulas de matemática de uma turma de oitavo ano e de uma turma de primeiro ano do Ensino Médio, ambas em escolas públicas de Campo Grande - MS. Neste artigo, temos por objetivo apresentar e discutir alguns movimentos de aprendizagem com o uso de Lousa Digital que ocorreram durante um estudo sobre área de retângulos, em uma aula de matemática de uma turma de Ensino Médio. A discussão será apresentada a partir do referencial teórico proposto na pesquisa de doutorado.

Neste texto, inicialmente, situamos nossa pesquisa no cenário investigativo sobre o uso da Lousa Digital. Na sequência discutimos elementos teóricos e metodológicos da pesquisa desenvolvida e alguns movimentos de aprendizagem em uma aula de matemática do Ensino Médio, com uso da Lousa Digital.

\section{Elementos teóricos e metodológicos da pesquisa}

Em nossa pesquisa de doutorado nos propusemos a investigar como ocorrem movimentos de aprendizagem com o uso de Lousa Digital em aulas de matemática. Para o desenvolvimento de tal investigação, propusemos uma construção teórica que denominamos na tese de Ciclo de Ações Coletivo. Tal proposta teórica tem como base elementos do Ciclo de Ações proposto por Valente (2005), da Psicologia Cultural (VALSINER, 2012) e também da obra de arte denominada Parangolé, do artista plástico Hélio Oiticica. Elementos estes que discutiremos brevemente, de modo a situar o leitor acerca da articulação teórica que fundamenta as análises de dados realizadas na tese e a discussão que apresentaremos neste artigo.

Inicialmente, nos orientamos pelos estudos de Valente (2005) para considerar que ao construir conhecimentos utilizando tecnologias digitais, o sujeito vivencia as ações de Descrição-Execução-Reflexão-Depuração, que são as ações que compõem o Ciclo de Ações proposto por Valente, mostrado na Figura 1. 
Figura 1 - Ciclo de ações que acontece na interação aprendiz-computador

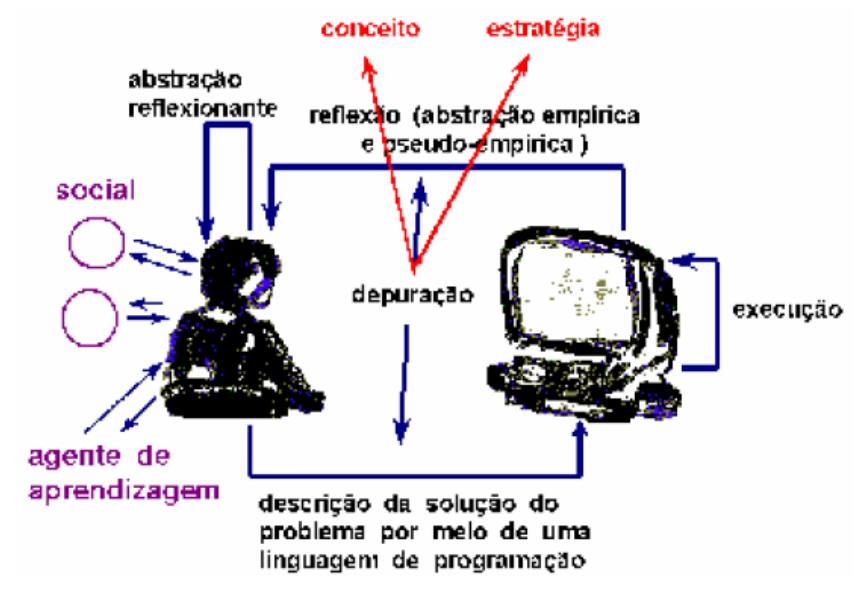

Fonte: Valente (2005, p. 66).

A ação de descrição acontece ao propor, por meio da tecnologia, uma possível solução para um problema proposto. O computador então executa o que foi descrito e apresenta na tela o resultado da descrição, a partir do qual é possível refletir sobre o que se visualiza na tela, caracterizando a ação de reflexão, e, caso não seja a solução desejada, o sujeito depura a solução e propõe uma nova descrição, iniciando um novo ciclo de ações.

Entretanto, ao considerarmos um processo de construção de conhecimento com a Lousa Digital e sua particularidade de uso coletivo, uma vez que consideramos que são vários indivíduos utilizando a mesma tecnologia simultaneamente (ela fica em local em que todos têm acesso, para manipular ou interagir com o que está sendo produzido e mostrado em tela), seja indo até a Lousa e operando-a manualmente, ou interagindo com o que se vê em tela, torna-se necessário compreender as particularidades desse processo para analisar e propor situações de aprendizagem com essa tecnologia.

Nesse sentido consideramos que diferentemente do Ciclo proposto por Valente (2005), no qual as reflexões e depurações (etapas fundamentais do processo de construção de conhecimento) são vivenciadas pelo sujeito a partir do retorno dado pelo computador, no uso da Lousa Digital essas ações podem ser vivenciadas pelo sujeito, também, a partir da interação com outros sujeitos participantes. Interações estas que podem ocorrer antes que uma Descrição seja levada à tela da Lousa Digital, a partir de diferentes propostas de descrição que, segundo elementos da Psicologia Cultural (VALSINER, 2012), consideramos que acontecem via processos de externalização e internalização, à medida que diferentes participantes externalizam suas ideias. Em outras palavras, entendemos que diferentes sujeitos podem externalizar diferentes ideias, propondo diferentes soluções para o problema e interagindo entre si, favorecendo processos de reflexão e depuração, antes mesmo que uma primeira Descrição seja levada à tela da Lousa Digital.

Em nossa proposta teórica, o movimento de interações ao qual nos referimos recebe o nome de Parangolé de Ações e configura-se como a primeira ação do Ciclo de Ações Coletivo (Parangolé de ações - Descrição - Execução - Parangolé de Ações - Nova Descrição...) que caracteriza o processo de aprendizagem com Lousa Digital. A escolha pelo termo Parangolé leva em consideração que, de acordo com a Psicologia Cultural, a cada interação com o meio 
e com outros o sujeito modifica seu mundo psicológico e, portanto, não será o mesmo a cada interação vivenciada. Isso implica que cada movimento de interação entre os sujeitos será único, uma vez que os sujeitos se modificam a cada movimento, a cada encontro.

Assim, na tentativa de representar esses movimentos que serão sempre únicos, nos valemos, na pesquisa, da obra de arte do artista plástico Hélio Oiticica (O Parangolé) como metáfora. Parangolés são capas feitas de tecido ou de plástico, para serem vestidas de maneiras diversas pelos participantes, estampadas com cores, palavras, fotos ou poemas interligados, que se revelam no movimento do participante que as veste. Desse modo, as cores antes contidas, tornam-se soltas e envolvem o corpo do participante que as faz brilhar no espaço por meio de danças e evoluções (SANTOS, 2008). Assim, conforme observado por Cavalcanti (2002, on-line)

[...] a cor ganha um dinamismo no espaço através da associação com a dança e a música. A obra só existe plenamente, portanto, quando da participação corporal: a estrutura depende da ação. A cor assume, desse modo, um caráter literal de vivência, reunindo sensação visual, táctil e rítmica. 0 participante vira obra ao vesti-lo, ultrapassando a distância entre eles, superando o próprio conceito de arte.

A proposta de Oiticica com os Parangolés é de que o espectador saia da sua condição de espectador para a condição de participante; que ao invés de contemplar as cores, vista-se delas. Na visão do artista não seria possível, portanto, ir a uma exposição de Parangolés. $\mathrm{O}$ Parangolé não é uma obra de arte, mas o "lugar" onde a experiência artística acontece. Isso faz com que a arte aconteça potencialmente na subjetividade do momento, dos gestos, como alguns dos movimentos representados na Figura 2.

Figura 2 - "Parangolés", Hélio Oiticica

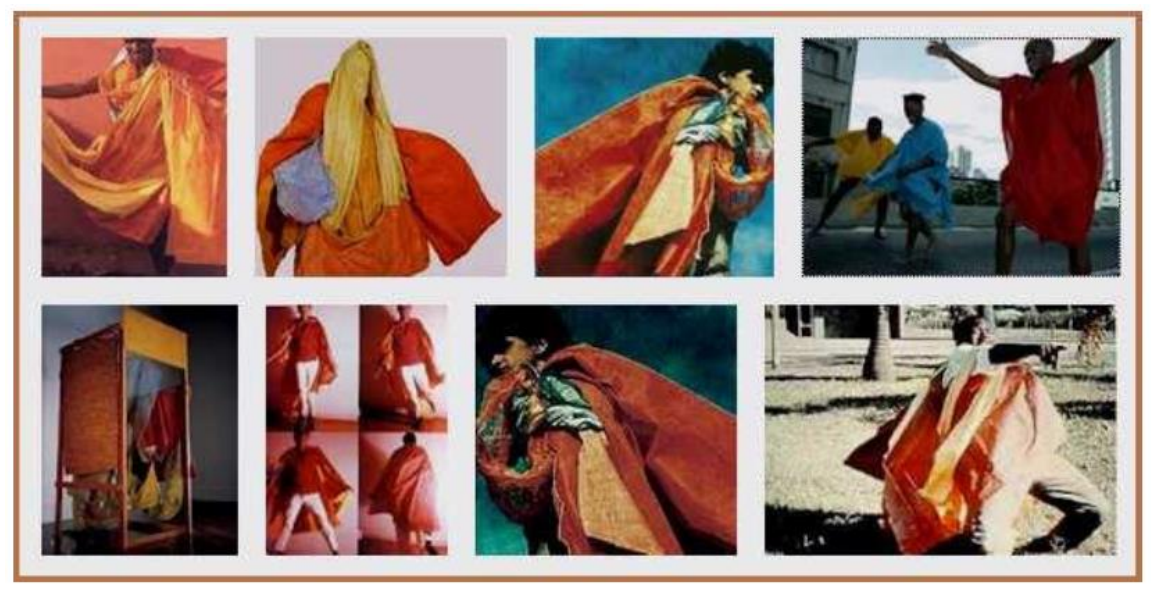

Fonte: Silva (2015, p. 5).

Conforme apontado por Silva (2015), o Parangolé não é uma obra fechada no objeto artístico, mas, ao contrário, se abre a todo momento para que sejam produzidos novos significados que jamais serão iguais àqueles produzidos no / pelo corpo do outro. Isso porque tal significação se constitui para além de aspectos científicos, culturais ou estéticos, fundamenta-se, sobretudo, nas vivências, sentidos, percepções e vontades de cada sujeito, e 
que os faz movimentar e dançar. "A obra não acontece sozinha, ela acontece em cada um, no olho, no ouvido, na pele, nessa necessária presença do corpo que se modifica a todo instante, que é contingente, que me faz ser eu" (SILVA, 2015, p. 2).

Diante disso, conforme aponta Santos (2008), o Parangolé não deixa mais espaço para definições pré-determinadas. A obra se mostra infinita, livre de qualquer imposição de padrões estéticos.

Por se valer de características como a unicidade, a subjetividade e também a (co)autoria, a obra de Oiticica tem norteado algumas discussões no âmbito educacional. Um de seus principais articuladores nesse contexto é Silva (2000), que propõe o conceito de Pedagogia do Parangolé, que por sua vez compreende o conhecimento como algo aberto e imprevisível, que deve ser construído de forma colaborativa e compartilhada, sem um caminho pré-determinado, a partir das significações que se constituem durante o processo.

Valendo-nos da metáfora do Parangolé e do ciclo de ações proposto por Valente (2005), consideramos que os movimentos de aprendizagem com Lousa Digital ocorrem como Ciclos de Ações Coletivos (Parangolé de ações - Descrição - Execução - Parangolé de Ações Nova Descrição...), conforme apresentamos na Figura 3 e discutimos em seguida.

Figura 3 - Ciclos de Ações Coletivos

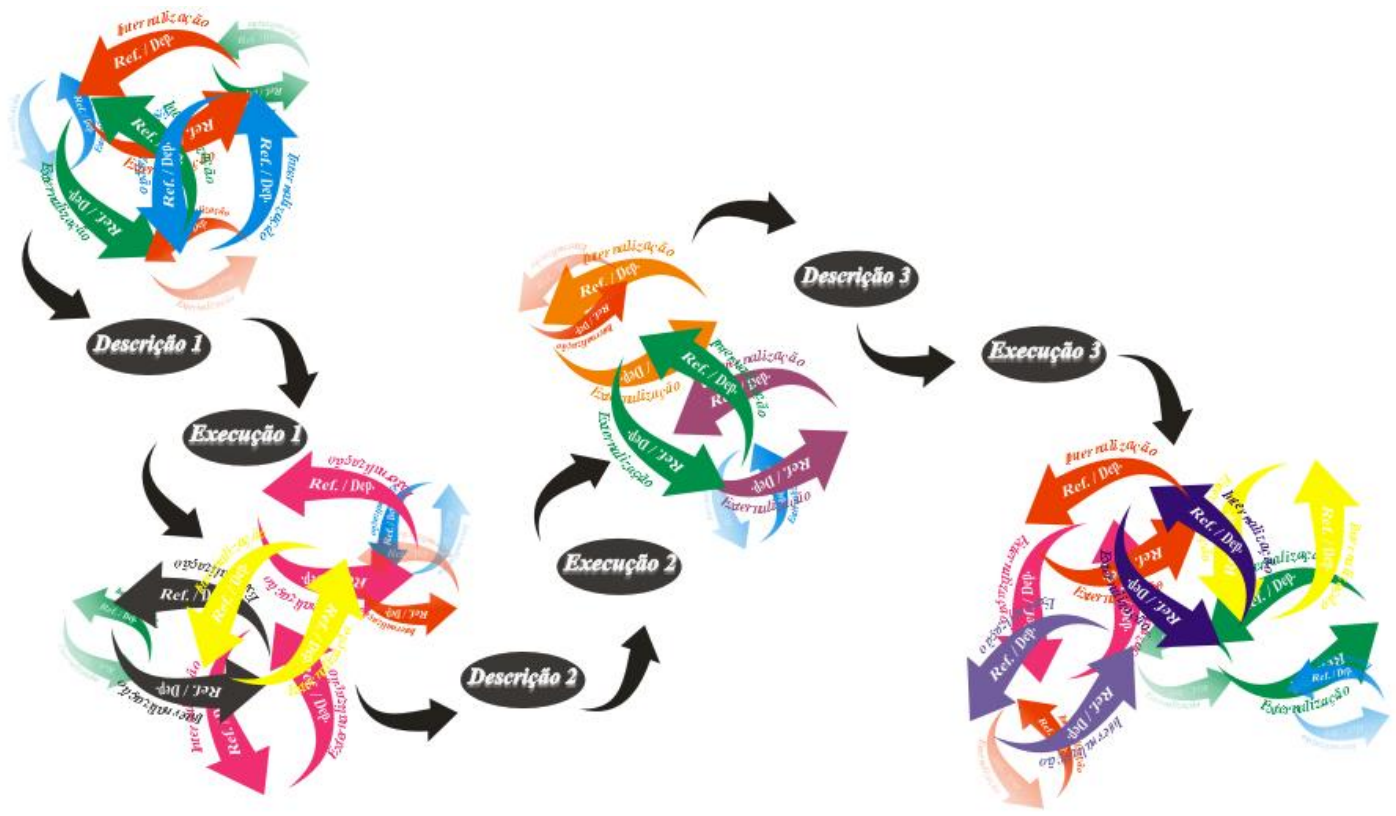

Fonte: Elaborado pelos autores.

$\mathrm{Na}$ proposta de representação do Ciclo de Ações Coletivo a primeira ação é denominada Parangolé de Ações e, conforme mencionado anteriormente, se caracteriza pelo movimento de interação entre sujeitos antes que uma descrição seja levada à tela da Lousa Digital.

Optamos por identificar, nos Parangolés de Ações, cada participante (que interage e vivencia reflexões e depurações) por uma cor diferente. Assim, tal como na obra de Oiticica, na qual as cores e formas que se revelam nos movimentos dos participantes são sempre únicas e não se repetem, cada Parangolé de Ações é, também, sempre único e assume cores e formas distintas, uma vez que se constitui na interação de diferentes sujeitos e que não é possível 
prever quantos e quais (ou de que maneira) sujeitos se mobilizarão a participar de cada movimento de aprendizagem.

A segunda ação do Ciclo de Ações Coletivo se dá com a Descrição, uma possível solução para o problema proposto, na tela da Lousa Digital. A tecnologia então Executa a Descrição realizada, apresentando em tela um retorno que pode desencadear novos movimentos de reflexões, depurações e interações, a partir do que se vê em tela, caracterizando um novo Parangolé de Ações e alimentando o Ciclo de Ações Coletivo.

Vale ressaltar que, no Ciclo de Ações Coletivo, assim como no Ciclo proposto por Valente (2005), as ações de Descrição e Execução são sempre comuns para todos os participantes, uma vez que só se pode levar à tela da Lousa Digital uma única Descrição por vez e, consequentemente, só se obtém uma única Execução. Desse modo, o Ciclo que propomos (exclusivo para Lousa Digital) se diferencia do Ciclo de Valente (2005) pelos movimentos que podem ocorrer tanto antes que uma descrição seja levada à tela da Lousa, quanto após o retorno dado pela tecnologia.

Diante de tal discussão, entendemos que para analisar movimentos de aprendizagem com Lousa Digital é necessário observar a constituição dos muitos Parangolés de Ações que se constituem a partir das interações que se estabelecem no desenvolvimento de atividades com esta tecnologia, e que vão alimentando Ciclos de Ações Coletivos. Observar a constituição destes movimentos, em suas diferentes composições de cores e formas, possibilita, portanto, investigar como ocorrem movimentos de aprendizagem que articulam processos individuais e coletivos de construção de conhecimentos, quando do uso da Lousa Digital.

Tendo explicitado alguns elementos teóricos da pesquisa, faz-se necessário discutir alguns aspectos metodológicos, em especial, os procedimentos de produção dos dados.

Os dados da pesquisa foram produzidos no segundo semestre de 2016 e no primeiro de 2017. Foram desenvolvidas aulas de matemática utilizando a Lousa Digital em uma turma de oitavo ano do Ensino Fundamental (em 2017) e em uma turma de Ensino Médio (que em 2016 cursava o primeiro ano e, em 2017, o segundo). No primeiro caso, o pesquisador era também o professor da turma. No segundo caso, a produção ocorreu por meio de uma parceria com o professor da turma em questão. Nesse último caso, tanto o planejamento das ações quanto o desenvolvimento das aulas foram realizados em parceria entre o professor da turma e o pesquisador (um dos autores deste artigo).

No oitavo ano, utilizando a Lousa Digital em conjunto com o software Geogebra, foram desenvolvidos estudos sobre coordenadas cartesianas, paralelismo, perpendicularidade de retas e sobre triângulos (condição de existência, classificações, propriedades). Com a turma de Ensino Médio, realizou-se estudos sobre área de figuras planas, utilizando a Lousa Digital e o Geoplano Digital, bem como estudos sobre trigonometria, com o uso do Geogebra. Para fins de registros, todas as aulas foram gravadas em áudio e vídeo que, aliados aos registros de observação do pesquisador constituíram os dados da pesquisa.

Neste artigo, discutimos alguns movimentos de aprendizagem que ocorreram, utilizando Lousa Digital, na turma do primeiro ano do Ensino Médio, em uma escola da rede Estadual de Ensino de Mato Grosso do Sul, na cidade de Campo Grande.

Com o intuito de contextualizar os conteúdos escolhidos e as atividades propostas aos alunos para estudos com a Lousa Digital, é importante mencionar que a escola em questão havia iniciado naquele ano um trabalho baseado na pedagogia de projetos, norteado por estudos sobre Educar pela Pesquisa, de Pedro Demo, Aprendizagem Baseada em Problemas, de Neusi Berbel, dentre outros. 
$\mathrm{Na}$ ocasião, os projetos da escola giravam em torno da temática "Meio Ambiente". $\mathrm{Na}$ matemática, objetivava-se estudar o conceito de função quadrática explorando ideias sobre otimização de áreas, uma vez que, discutindo problemas ambientais enfrentados pela comunidade escolar, foram levantadas questões acerca da relação entre alagamentos, permeabilidade do solo, área mínima permeável, dentre outras.

Nesse sentido, uma das primeiras ações planejadas para ocorrer com o uso da Lousa Digital foi um estudo sobre medida de área de figuras planas, utilizando o software Geoplano Digital $^{\beta}$ (Software que possibilita a representação de figuras planas e exploração de conceitos como vértices, arestas, área, perímetro, proporção e outros), para posteriormente passar às discussões que levariam ao conceito de função quadrática.

Para este encontro foram pensadas algumas tarefas no sentido de mobilizar e (re)construir conhecimentos sobre medidas de áreas de algumas figuras planas, como retângulos e triângulos. Nesse momento, já havia sido solicitado pelo professor Miguel ${ }^{4}$, em aulas anteriores, que cada aluno realizasse medições em suas residências e esboçasse uma planta baixa do terreno e da construção. $O$ objetivo era refletir sobre a relação entre a medida de área do terreno e a medida de área construída e, posteriormente, após o estudo de função quadrática, refletir sobre o aproveitamento da área construída (considerando-se o que estabelece a lei de permeabilidade do solo, estabelecida pela Prefeitura Municipal de Campo Grande e pesquisada previamente pelos alunos). Assim, poderiam ser discutidas questões como: se esta área poderia ser melhor aproveitada, se respeita os limites estabelecidos na lei, além de outras questões. Vale salientar que todas essas ações foram planejadas para ocorrer ao longo do último trimestre letivo.

Neste artigo são discutidos movimentos de aprendizagem que ocorreram em uma aula com essa turma do Ensino Médio, ao iniciarmos o estudo sobre medidas de área de retângulos. Vale ressaltar ainda que, nas ações desenvolvidas nesta escola, na maior parte do tempo, era o professor Miguel quem conduzia as discussões (previamente planejadas em parceria), enquanto o pesquisador (um dos autores deste artigo) se encarregava dos registros na forma de áudio, vídeo e anotações, bem como fazia algumas intervenções de modo a favorecer as discussões. A seguir, apresentamos uma análise dessa aula a partir do referencial teórico apresentado.

\section{Lousa Digital e área de retângulos: alguns movimentos de aprendizagem em uma aula de matemática no Ensino Médio}

O estudo sobre medidas de área de retângulos iniciou-se com o professor Miguel dando a tarefa aos alunos de representar na tela da Lousa Digital um retângulo de dimensões 2 e 3. Aqui vale mencionar que no início da aula o professor havia estabelecido, em diálogo com os alunos, um combinado de que nas construções que seriam solicitadas por ele as dimensões deveriam ser consideradas, respectivamente, na horizontal e na vertical, embora nada tenha sido comentado a esse respeito durante o planejamento de nossas ações.

Os primeiros movimentos se iniciaram com o aluno Matheus ${ }^{5}$ indo até a Lousa para fazer a representação solicitada. O aluno fez a representação mostrada na Figura 4 e, ao

\footnotetext{
${ }^{3}$ Disponível em http://www.inf.ufsc.br/ edla.ramos/projeto/geoplano/software.htm

${ }^{4}$ Nome fictício do professor da turma e parceiro na pesquisa.

${ }^{5}$ Os nomes dos alunos são fictícios.
} 
terminar, a aluna Marina se manifestou, iniciando as primeiras interações referentes àquela tarefa, conforme se pode observar no diálogo que segue. Aqui é importante mencionar que, assim como na proposta de representação dos Parangolés de Ações, nos diálogos apresentados, os nomes dos alunos também se encontram em cores distintas.

Figura 4 - Descrição feita por Matheus - Representação de um retângulo 2×3

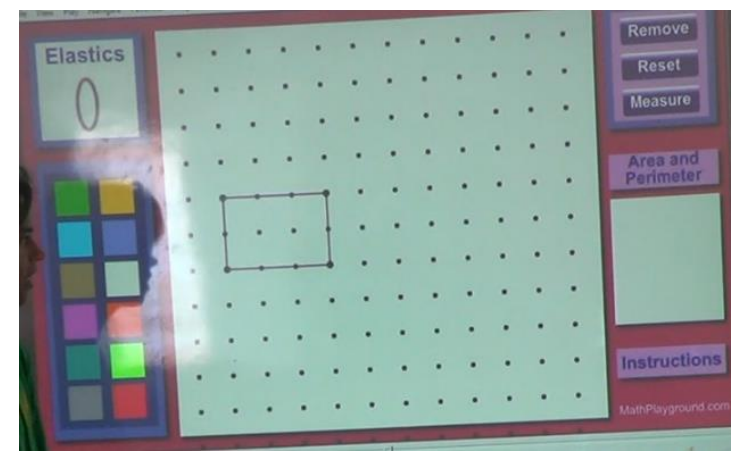

Fonte: Dados da Pesquisa.

Marina: Matheus, tá errado! É 2 por 3.

Matheus: E isso aqui é o que? É 2 por 2, por acaso?

Marina: Esse é 3 por 2!

Matheus: Então!

Professor: Pessoal, vamos lá! Matheus, veja bem! O que nós acabamos de combinar com relação às dimensões dos retângulos? Foi que a primeira dimensão solicitada seria da horizontal e a segunda seria da vertical.

Matheus: Ah, a primeira tem que ser da horizontal! É só fazer assim então [realizando uma nova descrição na tela, conforme Figura 5].

(Interação entre indivíduos, CARVALHO, 2019).

Figura 5 - Nova descrição feita por Matheus - Representação de um retângulo $2 X 3$

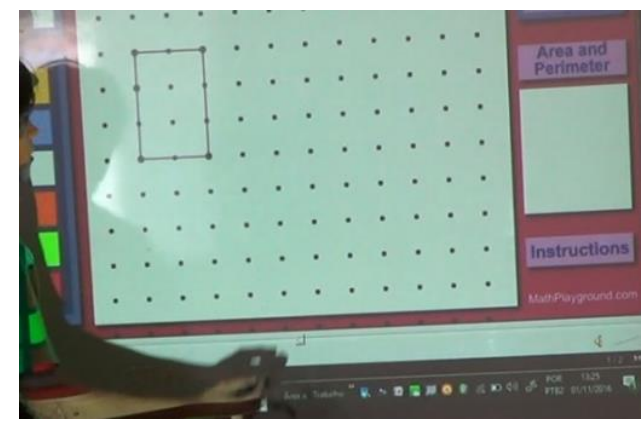

Fonte: Dados da Pesquisa.

Após a nova descrição feita na tela, o diálogo continuou com o professor questionando os alunos sobre a medida de área do retângulo construído, e iniciando registros no quadro branco ${ }^{6}$. Vejamos a continuidade do diálogo.

${ }^{6}$ Durante a aula, o professor realizava registros no quadro branco, referentes às dimensões das figuras representadas na Lousa Digital e às medidas de suas respectivas áreas. 
Professor: E agora, temos um retângulo 2 por 3 ?

Marina: Agora sim, "né"!

Professor: Então está ótimo, pessoal! Agora eu pergunto a vocês qual é a área desse retângulo. Júlia, você poderia responder pra gente? Qual é a área do retângulo construído pelo Matheus? Julia: Deixa eu ver... A área dele? É 6!

Professor: Seis, "o quê"?

Júlia: Seis, uai! Não sei (risos).

Professor: Seis o quê, turma?

Marina: Seis unidades quadradas.

Professor: Muito bom, Marina! Júlia, por que você diz que a área é seis?

Julia: Ué, porque é base vezes altura!

Professor: Só por isso?

Julia: Uai, é! (risos)

Professor: Pessoal, por que podemos afirmar que a área é seis?

Matheus: Porque "cabe" seis quadradinhos daqueles pequenos [referindo-se à unidade de área].

(Interação entre indivíduos, CARVALHO, 2019).

Naquele momento, o professor continuou sua interação com a aluna Julia, valendo-se da articulação entre os recursos tecnológicos (a Lousa Digital) e os recursos convencionais (o quadro branco e o pincel para quadro), representando com uma linha tracejada, por cima da representação de Matheus, uma unidade de área, conforme vemos na Figura 6. Ele poderia ter pedido para um aluno identificar uma unidade de área na representação do retângulo, usando os recursos do software, mas optou por usar o pincel, ele mesmo.

Figura 6 - Unidade de área representada pelo professor

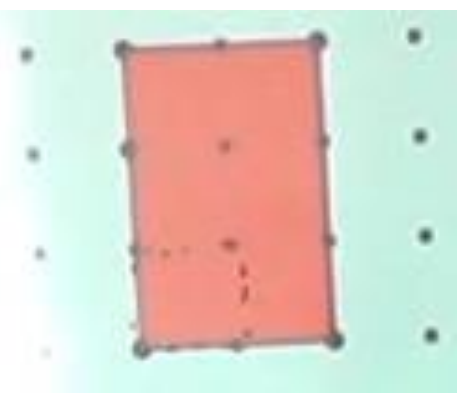

Fonte: Dados da Pesquisa.

Professor: Exatamente, Matheus! Julia, repare bem! Veja esse quadradinho [referindo-se à unidade de área]. Quantos desse você tem aqui dentro?

Julia: Um, dois... seis.

Professor: Seis. Cada quadradinho desse não corresponde a uma unidade quadrada? Por isso temos área de seis unidades quadradas. Tudo bem?

Julia: Tudo.

(Interação entre indivíduos, CARVALHO, 2019)

Neste diálogo, o professor ainda poderia ter aproveitado para questionar se as duas respostas eram corretas, bem como se há relação entre elas. Considerando os movimentos 
ocorridos no desenvolvimento da tarefa de representar na tela da Lousa Digital um retângulo com medidas 2 e 3, observamos, inicialmente, que os movimentos não se iniciaram a partir de propostas de descrição, nem mesmo de uma Descrição feita de forma coletiva, uma vez que o aluno Matheus apenas foi até a Lousa Digital e realizou a descrição em tela conforme julgava ser correto.

O fato de, neste caso, o Ciclo de Ações Coletivo que ali se desenvolveu ter se iniciado com uma descrição individual, pode estar associado a diferentes fatores que, embora não tenhamos elementos para confirmar a relação de nenhum deles com este fato, valem a pena ser pontuados aqui. Um deles seria a baixa complexidade da tarefa (representar um retângulo 2x3), que demandaria de poucas interações para ser resolvida. Outro, diz respeito às ações do professor, que poderia ter agido no sentido de questionar o aluno, antes que este realizasse a descrição em tela, acerca dos pontos nos quais ele pensava em fixar o elástico (os vértices da figura) para representar o retângulo solicitado, ou seja, sua proposta de descrição. Dessa maneira o aluno compartilharia, inicialmente, sua proposta de descrição e possibilitaria, a partir da troca de ideias sobre diferentes propostas de descrição, a constituição de um Parangolé de Ações antes que a descrição fosse levada à tela. Da maneira como ocorreu, poderíamos sugerir que o aluno Matheus iniciou apenas um Ciclo de Ações individual, o seu próprio ciclo, conforme Valente (2005).

Contudo, é importante ressaltar que, mesmo que o movimento tenha se iniciado a partir de uma descrição individual, esta descrição oportunizou reflexões e favoreceu externalizações que acabaram por constituir um Parangolé de ações e o início de um Ciclo de Ações Coletivo. Fato este que atribuímos à possibilidade que a Lousa Digital oferece de compartilhar uma descrição, mesmo que feita individualmente. Nesse sentido, observa-se que no uso da Lousa Digital é possível que Parangolés de Ações e Ciclos de Ações Coletivos se constituam, também, a partir do início de um Ciclo de Ações Individual.

O fato comentado acima se evidencia quando a descrição feita por Matheus favorece reflexões e externalizações da aluna Marina, que se manifestou argumentando estar incorreta a representação (não estava incorreta, apenas não atendia ao combinado da turma) feita por Matheus em tela. Por sua vez, a externalização de Marina também favoreceu reflexões de Matheus, que externalizou novos argumentos reforçando que sua representação estaria correta, ou seja, que se tratava de um retângulo de dimensões 2 e 3.

Aqui, cabe observar que o retângulo representado por Matheus, de fato possuía dimensões 2 e 3 . Contudo, não seguia o combinado sugerido pelo professor, de que a primeira medida seria representada na linha horizontal e a segunda na linha vertical, o que mostra que no momento do combinado entre o professor e os alunos, possivelmente Matheus não interagiu com as discussões ou não teve reflexões favorecidas a partir da fala do professor naquele momento. A fala de Marina, por sua vez, evidencia que a aluna vivenciou reflexões no momento do combinado com o professor, uma vez que, ao interagir com a representação de Matheus em tela, a aluna vivenciou as ações de reflexão e depuração da descrição feita pelo colega.

Nesse sentido, Marina fez novas externalizações afirmando que o retângulo representado seria um retângulo de dimensões 3 e 2, e que, considerando o combinado feito com o professor, seria diferente de 2 e 3, mesmo que representassem a mesma medida de área.

Naquele momento o professor, influenciado pelas discussões, agiu no sentido de favorecer novas reflexões a Matheus, reiterando o combinado anterior. A partir da fala do 
professor, Matheus vivenciou ações de reflexão e depuração de sua ideia inicial, conforme podemos observar no diálogo e na nova descrição feita em tela pelo aluno, mostrada na Figura 5.

Na sequência, após questionamento do professor acerca da nova descrição realizada por Matheus, a fala externalizada por Marina ["Agora sim, né!"] evidencia que a aluna pôde vivenciar novas reflexões a partir da interação com o novo retângulo representado em tela por Matheus.

As discussões continuaram com o professor direcionando o questionamento aos alunos sobre a medida de área da figura representada na tela da Lousa Digital. Naquele momento observa-se a primeira participação (por meio de externalizações) da aluna Julia, cujas falas nos possibilitam tecer alguns comentários.

Inicialmente vemos que Julia, a partir do questionamento do professor, interagiu com o objeto em tela e vivenciou reflexões que a fizeram externalizar a afirmação de que o retângulo possui medida de área igual a seis. Contudo, na sequência do diálogo, a próxima externalização feita por Julia ["Seis, uai! Não sei."] ao ser questionada pelo professor ["Seis o quê?"], nos dá indícios de que a aluna não vivenciou reflexões durante as discussões que ocorreram entre o professor e os alunos sobre a unidade de área, no início do estudo sobre quadrados.

Em contrapartida, as externalizações seguintes, que podem ser observadas no diálogo entre Julia e o professor, mostram que a interação com o objeto em tela, juntamente com os questionamentos do professor, oportunizaram à aluna vivenciar reflexões que a levaram a mobilizar conhecimentos (fórmula da área do retângulo) construídos em outros momentos de sua trajetória escolar, uma vez que, até aquele momento, nada havia sido mencionado sobre calcular área do retângulo multiplicando as medidas da base e da altura da figura.

Esses movimentos, mais uma vez, reforçam a relevância das ações do professor no sentido de favorecer discussões e oportunizar momentos de reflexão aos alunos. Nesse sentido, vemos que a ação do professor de, em meio à discussão com a aluna Julia, abrir o questionamento à turma ["Seis, o quê, turma?"], possibilitou que a aluna Marina vivenciasse reflexões a partir das discussões e externalizasse uma resposta ao questionamento do professor ["Seis unidades quadradas."].

Além de Marina, vemos ainda que as discussões entre Julia e o professor favoreceram também reflexões de Matheus que, a partir do questionamento do professor ["Por que podemos afirmar que a área é seis?"], vivencia as ações de reflexão e depuração do argumento de Julia ["Porque é base vezes altura."], afirmando que a área da figura correspondia a seis devido ao fato de caberem ali seis unidades quadradas. Vale ressaltar aqui que a depuração das ideias de Julia, por meio da externalização de Matheus, não significa que a resposta externalizada pela aluna estaria incorreta, mas que havia outros conhecimentos a serem construídos em relação à medida de área de um retângulo.

Em seguida, vemos que a ação do professor de representar uma unidade de área com uma linha tracejada, usando o pincel, aparentemente, oportunizou a Julia a vivência de reflexões acerca da medida de área da figura representada, para além da aplicação da fórmula "base vezes altura". Esta ação do professor também nos chama a atenção, uma vez que mostra a possibilidade de se articular diferentes recursos de modo a favorecer os movimentos de aprendizagem, não condicionando estes apenas ao uso da tecnologia, embora isso também pudesse ter sido realizado por meio do software, utilizando-se de outro "elástico" na representação de um quadrado de lado medindo uma unidade. 
A aula seguiu com o professor registrando no quadro branco as medidas dos lados do retângulo, bem como a medida da área e, logo após, solicitando aos alunos a representação de outros retângulos, para a continuidade dos estudos sobre áreas.

Os movimentos de aprendizagem que acabamos de discutir nos levam a tentar representar alguns Parangolés de Ações que se articulam na constituição de Ciclos de Ações Coletivos, a partir da realização da tarefa proposta, conforme mostra a Figura 7.

Figura 7 - Representação de Parangolés de Ações e Ciclos de Ações Coletivos

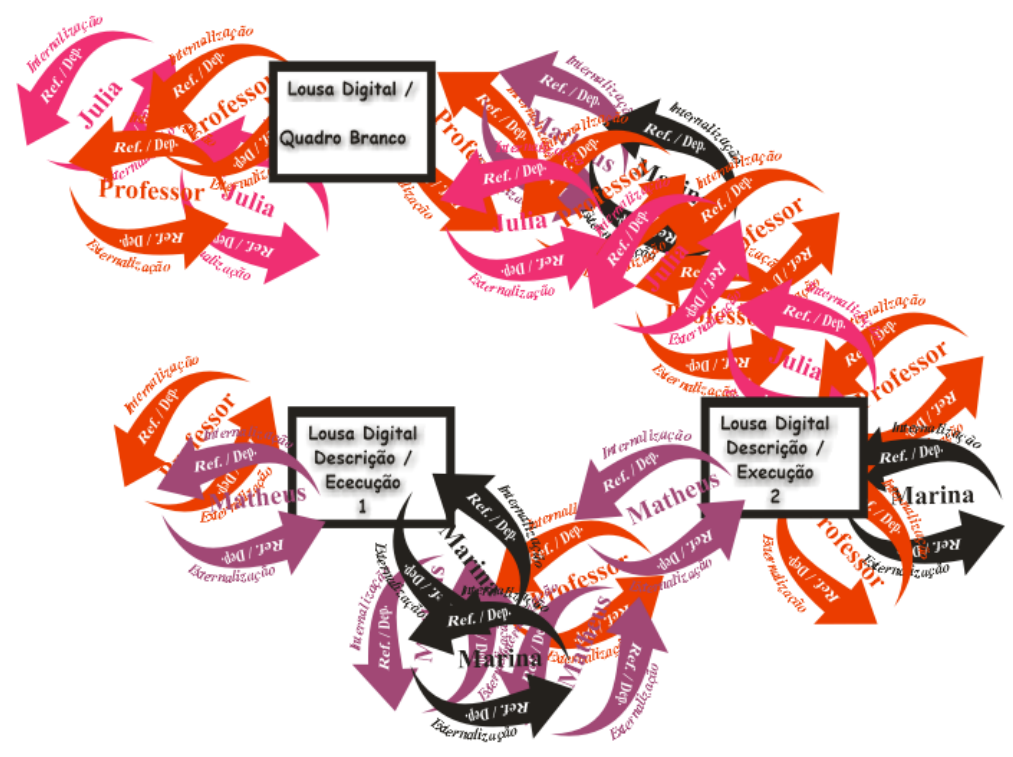

Fonte: Elaborado pelos autores.

As cores e formas que se evidenciam na representação da Figura 7 nos chamam a atenção com relação a outros Parangolés e Ciclos observados na análise de outros movimentos de aula na pesquisa realizada, nos quais observamos movimentos compostos por formas mais discretas e poucas cores, o que indica poucas externalizações e interações. Para exemplificar o que estamos comentando, apresentamos na Figura 8 uma representação de movimentos de aprendizagem, cuja análise não trazemos para este artigo, observados durante o estudo da medida de área de quadrados.

Figura 8 - Parangolés de Ações - Tarefa de representar um quadrado com lado medindo duas unidades

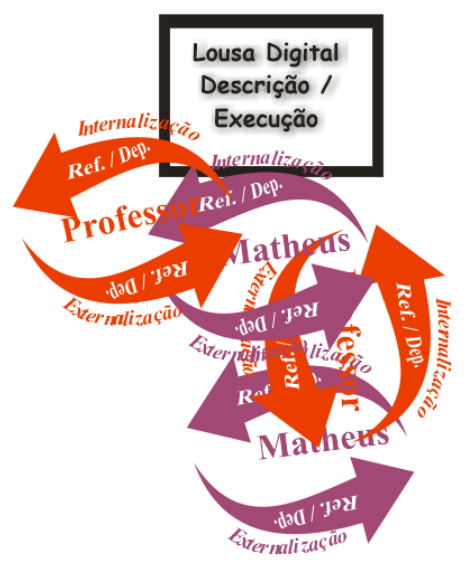

Fonte: Elaborado pelos autores. 
No caso da tarefa que discutimos neste artigo, é possível observar que, não fosse por uma ação do professor, a representação da Figura 7 também evidenciaria poucas cores e formas mais discretas, assim como no Parangolé de Ações mostrado na Figura 8. Referimonos aqui ao fato do professor ter direcionado um questionamento especificamente a uma aluna, Julia ["Julia, você poderia responder pra gente?"]. Ao fazer o direcionamento da pergunta, o professor incentivou a participação de uma aluna que até então não havia externalizado suas ideias. Observando a representação dos movimentos na Figura 7, vemos que a participação de Julia deu novas formas e coloridos àqueles movimentos. Isso nos leva a inferir que o professor tem papel fundamental enquanto sujeito ativo e participante dos movimentos de aprendizagem que ocorrem com o uso da Lousa Digital.

Outro elemento a ser discutido, diz respeito às tarefas propostas aos alunos. Acreditamos que a complexidade das tarefas solicitadas influencia nos movimentos de aprendizagem, ou seja, nas cores e formas de cada Parangolé, uma vez que diferentes tarefas podem oportunizar mais ou menos interações, mais ou menos externalizações e reflexões. Isso pode ser observado ao compararmos as representações das Figuras 7 e 8 , considerando as respectivas tarefas propostas, mas também em diversos outros momentos das análises da pesquisa. Podemos exemplificar tal consideração apresentando outra representação que se constituiu a partir da realização de outra tarefa (que não é objeto de discussão deste texto) durante o estudo da medida de área de triângulos. Vejamos a representação na Figura 9.

Figura 9 - Parangolés de Ações e Ciclos de Ações Coletivos - Estudo da área de triângulos

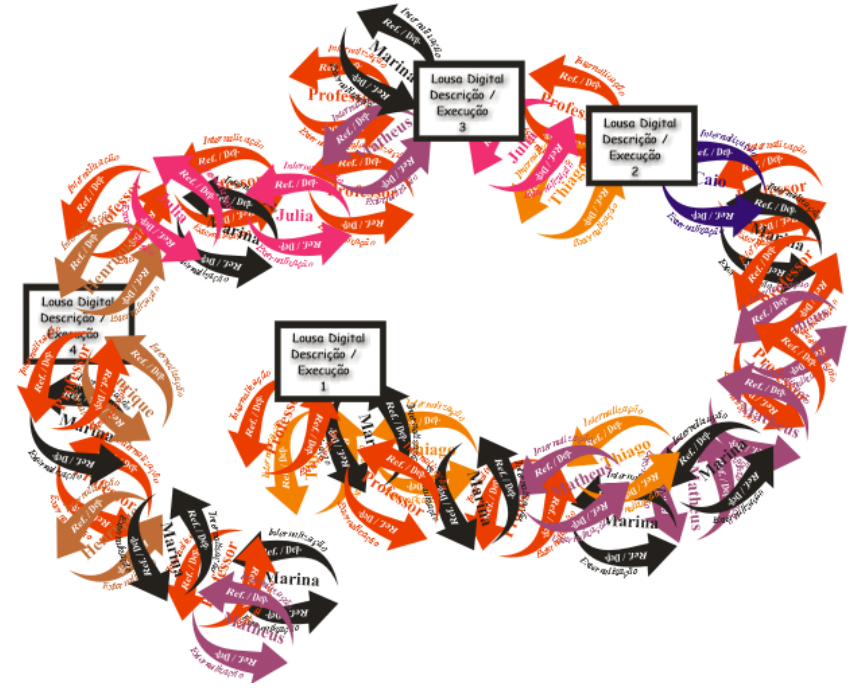

Fonte: Elaborado pelos autores.

A partir dos recortes de diálogos discutidos neste artigo e das representações de diferentes Parangolés de Ações e Ciclos de Ações Coletivos, observa-se que a cada tarefa proposta e realizada com uso da Lousa Digital, os movimentos de aprendizagem são únicos. São movimentos que se constituem, ganhando formas e cores, à medida que mais indivíduos se envolvem, externalizando suas ideias, e à medida que tais externalizações oportunizam reflexões de outros. 


\section{Algumas considerações}

Ao apresentar e discutir movimentos de aprendizagem com o uso de Lousa Digital que ocorreram durante um estudo sobre área de retângulos, em uma aula de matemática, com uma turma do 10 ano de Ensino Médio, observamos que o uso da Lousa Digital, ao favorecer o compartilhamento de ideias, oportunizou movimentos individuais e coletivos de aprendizagem. Movimentos que ocorrem como Parangolés de Ações, que se constituem a partir interações entre indivíduos, e destes com a Lousa Digital, e que vão constituindo Ciclos de Ações Coletivos.

Quanto à constituição dos Parangolés de Ações e dos Ciclos de Ações Coletivos foi possível observar que a característica da Lousa Digital como uma tecnologia de uso coletivo é fundamental para estes movimentos. Entretanto, fica claro que não é possível atribuir a constituição dos Parangolés e Ciclos Coletivos somente a esta característica da Lousa Digital. $\mathrm{Na}$ análise de dados foi evidenciado que a base da constituição dos Parangolés e dos Ciclos de Ações Coletivos são as externalizações realizadas pelos indivíduos, professor e alunos.

Em diferentes momentos da análise apresentada neste artigo, ficou claro também que as ações do professor tiveram papel fundamental na constituição dos movimentos de aprendizagem. É imprescindível que o professor se perceba como parte do Ciclo de Ações Coletivo, se permitindo influenciar e ser influenciado, refletir e oportunizar reflexões, de modo a favorecer a constituição dos Parangolés e Ciclos Coletivos.

Além das ações do professor, ficou claro também, observando as diferentes cores e formas do Parangolé constituído ao discutir a medida de área de retângulos, que os movimentos de aprendizagem se intensificam de acordo com o potencial da tarefa/questão proposta, que pode oportunizar discussões mais intensas entre os alunos e destes com o professor. Acreditamos ainda que é importante explorar diferentes softwares e aplicativos a serem projetados na Lousa Digital se quisermos dar mais vida, mais cores e formas aos Parangolés de Ações, ou seja, se quisermos potencializar os movimentos de aprendizagem com uso da Lousa Digital em aulas de Matemática.

Por fim, podemos concluir que as formas e cores dos Parangolés de Ações, que representam interações, reflexões e, portanto, movimentos de aprendizagem ao usarmos a Lousa Digital em sala de aula, possuem relação direta com diferentes fatores, tais como: as ações do professor, as tarefas propostas, e a escolha dos softwares e aplicativos. Esses três fatores, dentre outros, são fundamentais no favorecimento de externalizações, que movimentam os Ciclos Coletivos, produzidos a partir do compartilhamento de ideias, via Lousa Digital.

\section{Referências}

BERBEL, Neusi Aparecida Navas. A problematização e a aprendizagem baseada em problemas: diferentes termos ou diferentes caminhos? Interface-Comunicação, Saúde, Educação, v. 2, p. 139$154,1998$.

CARVALHO, Sérgio Freitas. Formação continuada em serviço e o uso da Lousa Digital em aulas de matemática: ações e reflexões de um grupo de professores. 2014. 150 f. Dissertação (Mestrado em Educação Matemática) - Universidade Federal de Mato Grosso do Sul. Campo Grande, 2014. 
CARVALHO, Sérgio Freitas de. Parangolés de ações e Lousa Digital: movimentos de aprendizagem em aulas de matemática. 2019. 176 f. Tese (Doutorado) - Curso de Doutorado em Educação Matemática, Universidade Federal de Mato Grosso do Sul, Campo Grande, 2019.

CARVALHO, Sérgio Freitas; SCHERER, Suely. O Uso da Lousa Digital: possibilidades de cooperação em aulas de matemática. Revista de Educação Matemática e Tecnologia Iberoamericana, v. 04, n. 03, p. 1-17. Recife, 2013.

CARVALHO, Sérgio Freitas; SCHERER, Suely. Integração da Lousa Digital em aulas de Matemática: análise da prática pedagógica de uma professora. Educação Matemática Pesquisa, v. 16, n. 02, p. 577-597. São Paulo, 2014.

CAVALCANTE, Jardel Dias. Parangolé: anti-obra de Hélio Oiticica. Digestivocultural, São Paulo, p. 1, 2002. Disponível em:

<https://www.digestivocultural.com/colunistas/coluna.asp?codigo=856\&titulo=Parangole:_antiobra_de_Helio_Oiticica>. Acesso em 12 jun. 2017.

COSTA, Dilermando Moraes; PUGGIAN, Cleonice; VILAÇA, Márcio Luiz Correa. Lousa digital no ensino de língua inglesa: o que os professores dizem sobre sua prática? InterSciencePlace, v. 11, n. 4, 2017.

DEMO, Pedro. Formação permanente de formadores: educar pela pesquisa. MENEZES, Luis Carlos (Org.) Professores: Formação e profissão. Campinas: Autores Associados, São Paulo, NUPES, 1996.

FISCARELLI, Silvio Henrique; MORGADO, Camila Lourenço; FÉLIX, Monique Alves. Objetos de aprendizagem e lousas digitais interativas: uma proposta de avaliação de objetos de aprendizagem para ensino de matemática. Ibero-Americana de Estudos em Educação, v. 11, n. 25, p. 350-362, 2016.

FLORES, Maria Lucia Pozzatti; MUSSOI, Eunice Maria; FALKEMBACH, Gilse Antoninha Morgental. Recursos tecnológicos para a docência no século XXI. In: CONGRESSO INTERNACIONAL DE EDUCAÇÃO E TECNOLOGIAS, 4., 2018, São Carlos, Anais. São Carlos: UFSCAR, 2018. Disponível em:

<https://cietenped.ufscar.br/submissao/index.php/2018/article/view/233>. Acesso em: 20 fev. 2019.

MAZZI, Lucas Carato; SIQUEIRA, Mirela Nunes; BORBA, Marcelo de Carvalho. As possibilidades e as limitações do uso da lousa digital na Educação Matemática. Perspectivas da Educação Matemática, v. 05, n. 10, p. 07-30. Campo Grande, 2012.

NAVARRO, Eloisa Rosotti; KALINKE, Marco Aurélio. Investigando o uso da Lousa Digital na Rede Estadual De Ensino Com o Apoio de um Curso de Formação. In: ENCONTRO NACIONAL DE EDUCAÇÃO MATEMÁTICA, 12., 2016, São Paulo. Anais. São Paulo: SBEM, 2016. Disponível em <http://www.sbembrasil.org.br/enem2016/anais/comunicacoes-cientificas-9.html>. Acesso em: 25 jul. 2017.

RIBEIRO, Mariana Silva Nogueira; KALINKE, Marco Aurélio; DOS SANTOS, Luciane Mulazani. Algumas possibilidades de apropriações da lousa digital por professores em sala de aula. Educação, Formação \& Tecnologias, v. 10, n. 1, p. 74-87, 2017. 
SANTOS, Nívia Valéria. A vanguarda em Hélio Oiticica: uma revolução no conceito estrutural de obra de arte. In: ENCONTRO DE HISTÓRIA DA ARTE, 4., 2008, Campinas. Anais. Campinas: UNICAMP, 2008. Disponível em:

<https://www.ifch.unicamp.br/eha/atas/2008/DOS\%20SANTOS,\%20Nivia\%20Valeria\%20\%2OIVEHA.pdf>. Acesso em: 15 mar. 2016.

SEBASTIÃO, Danubia; GIACOMAZZO, Graziela Fatima. Lousa digital e educação matemática: análise das produções científicas na perspectiva sociotécnica. Educação Matemática em Revista, p. 64-79, 2018.

SILVA, Henrique et al. Um mapeamento sistemático sobre o uso da Lousa Digital Interativa no processo de ensino-aprendizagem. In: WORKSHOP DE INFORMÁTICA NA ESCOLA, 23., 2017, Recife. Anais. Recife: SBC, 2017. Disponível em: <https://br-ie.org/pub/index.php/wie/article/view/7334>. Acesso em: 08 abr. 2018.

SILVA, Marco. Pedagogia do Parangolé: novo paradigma em educação presencial e online. In: SILVA, Marco (Org.). Sala de Aula Interativa. Rio de Janeiro: Ed. Quartet, 2000.

SILVA, Paula F. Parangolés e pós-modernidade: corpos envolvidos, corpos envolventes. Intercâmbio dos Congressos de Humanidades, n. 16, p. 557-566, 2015.

VALENTE, José Armando. A Espiral da Espiral de Aprendizagem: o processo de compreensão do papel das tecnologias de informação e comunicação na educação. 2005. Tese (Livre Docência) Universidade Estadual de Campinas. Campinas, 2005.

VALSINER, Jaan. Mundos da mente, mundos da vida: fundamentos da psicologia cultural. Porto Alegre: Artmed, 2012. 